\title{
In reply: Management of thin melanoma
}

Dear Editor,

In the letter entitled "Management of thin melanoma," Drs. Pusiol and Piscioli outline an algorithm for classification of melanoma into one of three types; nontumorigenic microinvasive radial growth phase (RGP) thin melanoma, tumorigenic early vertical growth phase (VGP) thin melanoma, or uncertain potentially tumorigenic thin melanoma. Further, the authors suggest that treatment decisions regarding performance of sentinel lymph node biopsy (SLNB) be based on this classification alone, with the recommendation that SLNB be performed for any VGP thin melanoma with a potential for regional nodal metastasis.

The decision to perform SLNB has historically been based on the probability of finding a positive sentinel lymph node using independent prognostic variables of tumor and patient characteristics. In our study of 510 patients with 512 melanoma lesions Breslow thickness $0.75-0.99 \mathrm{~mm}$, univariate analysis showed age $\leq 45$, Breslow depth $\geq 0.85 \mathrm{~mm}$, mitotic rate $>1 / \mathrm{mm}^{2}$, and ulceration to be significantly associated with nodal disease (either positive SLNB or nodal recurrence in the follow up period). ${ }^{1}$ To our knowledge, RGP and VGP have not been shown to be independent prognostic indicators of risk of nodal metastasis and, although the risk is low, it has been shown that very early thin lesions and even those interpreted as melanoma in situ can metastasize. ${ }^{2}$

Given that SLNB is a surgical test with associated risks, the recommendation to perform SLNB has been and should continue to be based on the probability (percentage) and not the possibility (yes/no) of regional lymph node disease. As such, we feel strongly that the decision to perform SLNB should be based upon a reasonable evaluation of the likelihood of potential benefit appropriately weighed against the surgical risk.

\section{CONFLICTS OF INTEREST}

None.

\section{ORCID}

Alison B. Durham iD http://orcid.org/0000-0002-5051-5374

Sincerely,

Alison B. Durham, $\mathrm{MD}^{1}$ Jennifer L. Schwartz, MD ${ }^{1}$
Lori Lowe, $\mathrm{MD}^{1,2}$

Lili Zhao, $\mathrm{PhD}^{3}$

Andrew G. Johnson, BA ${ }^{4}$

Kelly L. Harms, MD, $\mathrm{PhD}^{1}$

Christopher K. Bichakjian, MD ${ }^{1}$

Amy P. Orsini, $M D^{1}$

Scott A. McLean, MD, PhD ${ }^{5}$

Carol R. Bradford, MD ${ }^{5}$

Mark S. Cohen, $\mathrm{MD}^{6}$ Timothy M. Johnson, MD ${ }^{1,5,6}$

Michael S. Sabel, MD ${ }^{6}$

Sandra L. Wong MD, $\mathrm{MS}^{7}$

${ }^{1}$ Department of Dermatology, University of Michigan Hospital, Ann

Arbor, Michigan

${ }^{2}$ Department of Pathology, University of Michigan Health System, Ann Arbor, Michigan

${ }^{3}$ Department of Biostatistics, University of Michigan Health System, Ann Arbor, Michigan

${ }^{4}$ University of Michigan Medical School, Ann Arbor, Michigan

${ }^{5}$ Department of Otolaryngology, University of Michigan Health System,

Ann Arbor, Michigan

${ }^{6}$ Department of Surgery, University of Michigan Health System,

Ann Arbor, Michigan

${ }^{7}$ Department of Surgery, Dartmouth-Hitchcock Medical Center and Geisel School of Medicine at Dartmouth, Lebanon, New Hampshire

Correspondence

Alison B. Durham, Department of Dermatology, University of Michigan Health System, 1500 E. Medical Center Dr, UH South

F7672, Ann Arbor, MI 48109-5218.

Email: ambates@med.umich.edu

\section{REFERENCES}

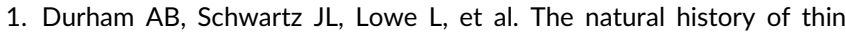
melanoma and the utility of sentinel lymph node biopsy. J Surg Oncol. 2017.

2. Bax MJ, Johnson TM, Harms PW, et al. Detection of occult invasion in melanoma in situ. JAMA Dermatol. 2016;152:1201-1208.

How to cite this article: Durham AB, Schwartz JL, Lowe L, et al. In reply: Management of thin melanoma. J Surg Oncol. 2018;117:536. https://doi.org/10.1002/jso.24858 